\title{
"It's what we think we know that keeps us from learning!"- Claude Bernard
}

\author{
Ali N. Ibrahimiye, MD
}

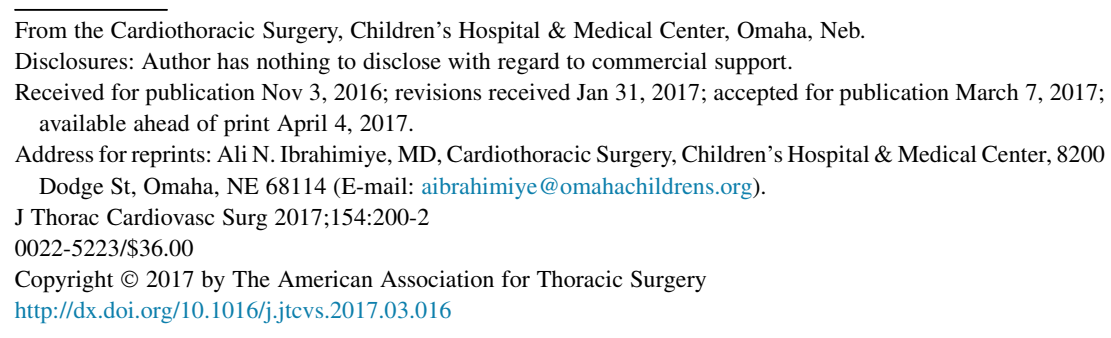

The quotation I borrowed for the title of this piece belongs to the great French physiologist Claude Bernard. Bernard was not only a great physiologist who tirelessly practiced vivisection to gain better understanding of physiology but also became one of the founding fathers of scientific experimentation as we know it. He was one of the most knowledgeable, well-educated men of his time, and yet he worked hard all his life to learn more. He said, "It's what we think we know that keeps us from learning."

Before we move any further, we need to agree on one thing. To gain new knowledge effectively, one has to accept that he/she lacks knowledge. This may seem intuitive and simple, but it is the first step. In my humble opinion, one of the main reasons why cardiothoracic surgery is so interesting and fun is that we are constantly being challenged with new information and techniques. It's a very dynamic field. We cannot simply rely on what we have been taught in training. We need to acquire new knowledge and try to find better techniques to help our patients. I think, some surgeons who have been outstanding throughout their training fail to make the next leap simply because they believe they know how to perform certain tasks and don't need further supervision or help. "Knowing how to perform" does not equate to "being able to perform," the latter involving not only knowledge but also innate ability, dexterity, composure, and experience, to name just a few contributing factors.

The next step is to acquire knowledge. It's easier said than done. During surgical training, there are scheduled lectures, courses, books you are expected to read, and examinations you need to pass. As long as you get on with the program, you learn. When one becomes an attending, no one forces you to read or study. Nobody quizzes you in the operating room. Therefore, learning after residency may be more challenging than one would think. Learning is not attained by chance; it must be sought for with enthusiasm and attended with diligence.

We can organize the different ways we can continue to learn after formal training in 4 broad categories: continuing medical education, clinical practice, teaching, and mentorship.

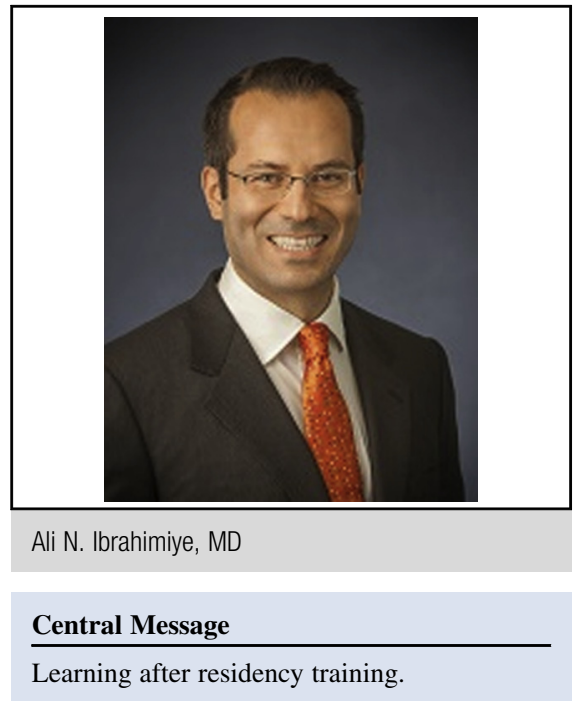

See Editorial Commentary page 203.

\section{CONTINUING MEDICAL EDUCATION}

In my opinion, this is one of the most efficient ways to maintain a fund of knowledge and acquire new knowledge because it doesn't rely on supervision or assistance from someone else. Continuing medical education is not only necessary but also mandatory. Last year, I took my adult cardiothoracic surgery boards. To prepare for my examination, I read Sabiston's textbook cover to cover, completed the latest version of Self Education Self Assessment in Thoracic Surgery (SESATS), and took a board review course. I felt well prepared for the examination and was able to pass. I am currently studying for my congenital cardiac surgery boards. Again, I am reading Dr Jonas' textbook cover to cover and answering SESATS questions because there is no test prep resource specifically for the congenital boards. Of course, I learn the most through my daily practice of congenital heart surgery. Our department also has a subscription to the Journal, The Annals of Thoracic Surgery, Journal of the American College of Cardiology, Circulation, and The New England Journal of Medicine. I skim through the index for each journal and mark the articles I like for copying. Naturally, I spent more time reviewing and reading the Journal and The Annals of Thoracic Surgery. The journals have been the primary resource for me to acquire new knowledge and keep up with the latest developments in our constantly evolving specialty. 
I think annual society meetings provide the ideal environment to meet our colleagues, share ideas, and learn new ideas to implement in our clinical practice. We, as a group, make an effort to attend as many national meetings as we can. We take turns, so that each partner is able to go to at least 2 meetings a year.

\section{CLINICAL PRACTICE: LEARNING FROM OUR PATIENTS}

Our patients are our most important teachers. It is a medical cliché but very true. Especially, in pediatric cardiac surgery, no 2 patients are the same. Every patient is unique, so that we as surgeons need to adapt and adjust our strategy accordingly. I was taught early on in my training to carefully review every patient the day before and mentally prepare for the surgery before the lights when out. It is my practice to review the surgical plan and look through all diagnostic studies on my own. If something is not clear or I have a question, I review the studies with the expert cardiologist. Once I feel completely comfortable with all aspects of the anatomy, I review our operative plan with my senior partner. He almost always has insightful suggestions and warns me about potential pitfalls. This simple routine has helped me a lot during the early months as an attending surgeon and reinforced my confidence.

\section{LEARNING BY TEACHING}

Throughout my training, I learned various things from different teachers. I remember all my teachers with respect and gratitude whether it is the chief resident who taught me how to close skin or the physician assistant who took me through my first sternotomy. I think it takes the highest level of comfort and confidence in your skills to take someone else through a procedure. The most rewarding aspect of my chief years both as a general surgery resident and a cardiac surgery fellow was taking junior residents through cases or parts of a case. I certainly miss this experience in my current practice, because we don't have any fellows or residents rotating through our service in congenital cardiac surgery. But teaching doesn't have to be limited to surgeons. Several of our intensive care unit nurses came to me concerned that they didn't quite understand the anatomy and the surgical repairs we do. I think we can all agree that if the care team understands what is wrong with the patient, they can take better care of the patient. That prompted us to develop a lecture series for the entire care team. I learned a lot during the process of developing the curriculum, preparing for the lectures, and making presentations. And we will continue to offer this lecture series in 4-month cycles, so I will need to update my slides to reflect any changes in treatment algorithms and new studies that were published in the interim. So, I encourage all junior attendings to find a way to teach. It is the best way to stay up to date, and it is the only way of learning that helps others in your team.

\section{MENTORSHIP}

When successful academic surgeons are asked about the factors that played a significant role in their career, mentorship is uniformly quoted as a key element. Mentorship is essential for career satisfaction and retention for the institution. ${ }^{1-3}$ But how do you find a good mentor and how does one define good mentorship. I haven't seen any CTSNet job postings that say "good mentor looking for dedicated apprentice!" A recent study showed that approximately half of departments of surgery have established mentorship programs and that, among those that have them, the structure varies significantly.

First of all, what is mentorship? Here is how the Oxford English Dictionary defines mentorship. Mentorship is a relationship in which a more experienced or more knowledgeable person helps to guide a less-experienced or lessknowledgeable person. The mentor may be older or younger than the person being mentored, but she or he must have a certain area of expertise. It is a learning and development partnership between someone with vast experience and someone who wants to learn.

Both the mentor and the protégé have to be committed to the partnership, but the partnership comes with a set of ground rules both parties must agree on. ${ }^{4,5}$

a. "It's what we think we know that keeps us from learning!" The protégé must seek mentorship and be willing to embrace criticism.

b. In a specialty such as cardiothoracic surgery in which the stakes are very high, the goal should be to minimize errors during the learning curve period. However, in reality even the most experienced surgeons sometimes make mistakes. It is important to keep in mind that criticism by the mentor should be constructive with the goal of teaching the protégé a valuable lesson.

c. Mentorship is about the protégé. Although mentoring offers certain benefits to the mentor such as self-validation and establishing a legacy, the primary focus of the mentoring process is on the person being mentored.

d. The mentoring process should not be used as a vehicle to exploit the person being mentored.

e. Trust is critical in a healthy mentoring relationship. Matters discussed between the mentor and the protégé must remain confidential.

f. Mentoring takes time, the most valuable resource. A mentor has to understand and willing to make the time commitment.

g. A common misconception is that the protégé brings questions and the mentor provides the answers. In a good mentoring program, the mentor should not provide all the answers but ask the protégé questions and help him or her figure out the answers on his/her own. 
h. Honest feedback is very important. Feedback should not be degrading, but it also does not need to be sugarcoated.

Now, I would like to give an example from my daily routine to illustrate some of the points I have tried to make. From day 1, my senior partner Dr James Hammel and I agreed that I would scrub in every case and assist him. This is a great opportunity for him to share his experience with me, while I learn his routine and familiarize myself with my new operating room. I also would join him in his patient consultations and follow-up visits. With the work hour limitations, cardiac surgery training is heavily weighted toward experience in the operating room, and I don't believe trainees spent enough time in the clinic or talking to families, definitely not with parents who just learned their child has a heart defect. After our weekly cardiac care conference, we return to his office and go over the surgical cases. He has been giving me cases appropriate for my level from day 1 , but he also makes sure he is available on the day of the surgery. We agreed that he would be available to assist or supervise until I tell him that I feel 100\% confident.

The day before the surgery, I review the case and go over diagnostic imaging. Then I present the case to my partner who usually asks me some questions about the case to get me thinking about potential pitfalls and complications. This is our mental prep routine.

In our operating room, we use a video system that allows my partner to watch the surgery from his office. Regardless,
I always ask the circulator to page him before I crossclamp to make sure he is available. If I encounter a problem or an unexpected finding, I ask him to join me.

Once I finish the case, I go to his office and we go over the case. The point of this debriefing is "What did I learn?" and "How can I do it better next time?" There is always room for improvement. Even if everything went as smooth as it possibly can, one can make the incision smaller next time.

In summary, the transition from training to becoming an attending surgeon is very challenging. It is a critical turning point in one's career. Only with the right attitude and a capable mentor who is willing to invest can one ensure a satisfactory and successful practice. Therefore, I urge all my junior colleagues hunting for their first job to get their priorities straight. The first job is the most important job, and finding a good mentor is the most important factor while deciding on a first job. Good luck!

\section{References}

1. Kibbe MR, Pellegrini CA, Townsend CM Jr, Helenowski IB, Patti MG. Characterization of mentorship programs in department of surgery in the United States. JAMA Surg. 2016;151:900-6.

2. Ries A, Wingard D, Gamst A, Larsen C, Farrell E, Reznik V. Measuring faculty retention and success in academic medicine. Acad Med. 2012;87: 1046-51.

3. DeCastro R, Griffith KA, Ubel PA, Stewart A, Jagsi R. Mentoring and the career satisfaction of male and female academic medical faculty. Acad Med. 2014;89: 301-11.

4. Dalcort CJ. Mentoring: establishing a legacy, shaping the future. Mil Rev. 2002;82: 35-9.

5. Johnson W, Band R. The Elements of Mentoring. New York, NY: Palgrave MacMillan; 2004. 